\title{
Reinnervation of Late Postnatal Purkinje Cells by Climbing Fibers: Neosynaptogenesis without Transient Multi-Innervation
}

\author{
Mathieu Letellier, ${ }^{1}$ Yannick Bailly, ${ }^{2}$ Valérie Demais, ${ }^{3}$ Rachel M. Sherrard ${ }^{4}$ Jean Mariani, ${ }^{1,5}$ and Ann M. Lohof ${ }^{1}$ \\ ${ }^{1}$ Université Pierre et Marie Curie-Paris, Unité Mixte de Recherche (UMR) 7102-Neurobiologie des Processus Adaptatifs (NPA), and Centre National de la \\ Recherche Scientifique (CNRS), UMR 7102-NPA, F-75005 Paris, France, ${ }^{2}$ Neurotransmission et Sécrétion Neuroendocrine, UMR 7168 Institut des \\ Neurosciences Cellulaires et Intégratives, CNRS, and ${ }^{3}$ Plateforme d'Imagerie In Vitro, Institut Fédératif de Recherche 37 des Neurosciences, Université \\ Louis Pasteur, F-67084 Strasbourg, France, ${ }^{4}$ School of Anatomy and Human Biology, University of Western Australia, Crawley 6009, Australia, and \\ ${ }^{5}$ Assistance Publique-Hôpitaux de Paris Hôpital Charles Foix, Unité d’Explorations Fonctionnelles, F-94200, Ivry sur Seine, France
}

Synaptic partner selection and refinement of projections are important in the development of precise and functional neuronal connections. We investigated the formation of new synaptic connections in a relatively mature system to test whether developmental events can be recapitulated at later stages (i.e., after the mature synaptic organization has been established), using a model of postlesional reinnervation in the olivo-cerebellar pathway.

During the development of this pathway, synaptic connections between climbing fibers (CFs) and Purkinje cells (PCs) are diffuse and redundant before synapse elimination refines the pattern. The regression of CFs during the first 2 postnatal weeks in the rat leads to mono-innervation of each PC. After unilateral transection of the rat olivo-cerebellar pathway and intracerebellar injection of BDNF $24 \mathrm{~h}$ after lesion, axons from the remaining inferior olive can sprout into the deafferented hemicerebellum and establish new contacts with denervated PCs at later developmental stages. We found that these contacts are first established on somatic thorns before the CFs translocate to the PC dendrites, recapitulating the morphological steps of normal CF-PC synaptogenesis, but on a relatively mature PC.

However, electrophysiology of PC reinnervation by transcommissural CFs in these animals showed that each PC is reinnervated by only one CF. This mono-innervation contrasts with the reinnervation of grafted immature PCs in the same cerebellum. Our results provide evidence that relatively mature PCs do not receive several olivary afferents during late reinnervation, suggesting a critical role of the target cell state in the control of CF-PC synaptogenesis. Thus, synapse exuberance and subsequent elimination are not a prerequisite to reach a mature relationship between synaptic partners.

Key words: cerebellum; synaptogenesis; reinnervation; Purkinje cell; climbing fiber; synapse elimination

\section{Introduction}

A striking feature of the CNS is the high degree of precision in the wiring of its diverse neuronal populations. Once an axonal growth cone has reached a target field, how do synaptic partners interact to achieve this precise connectivity? In the mammalian brain, broad initial projections are refined to give more precise patterns of connectivity (Purves and Lichtman, 1980; Katz and Shatz, 1996). Are these appropriate synaptic connections re-

\footnotetext{
Received 0ct. 23, 2006; revised March 21, 2007; accepted April 16, 2007.

This work was supported by funds from the Centre National de la Recherche Scientifique (CNRS), the Université Pierre et Marie Curie, the Institut pour la Recherche sur la Moelle Epinière et l'Encéphale, and the Fondation NRJ. The international collaboration was supported by the Fondation Simone et Cino de Duca and by a Programmes Internationaux de Coopération Scientifique Grant from the CNRS. We thank Regeneron/Amgen partners for providing some of the BDNF. We thank Dr. Florence Frédéric for help with statistical analysis and Dr. Isabelle Dusart for assistance with the graft experiments.

Correspondence should be addressed to Dr. Ann M. Lohof, Université Pierre et Marie Curie, Unité Mixte de Recherche 7102-Neurobiologie des Processus Adaptatifs, 9 quai St. Bernard, case 14, 75005 Paris, France. E-mail: ann.lohof@snv.jussieu.fr.

DOI:10.1523/JNEUROSCI.0452-07.2007

Copyright $\odot 2007$ Society for Neuroscience $\quad$ 0270-6474/07/275373-11\$15.00/0
}

formed in cases of reinnervation? We wanted to assess the influence of target cell maturation in synapse formation and stabilization by asking whether events of early synaptogenesis are reproduced when reinnervation occurs in a relatively mature system. To answer this question, we used a denervation-reinnervation model to study neosynaptogenesis after the period of normal developmental synaptic refinement.

The olivo-cerebellar system is a good model to address these questions for a number of reasons. The mature olivo-cerebellar connection displays a one-to-one relationship between the afferent climbing fiber (CF) and the target Purkinje cell (PC) (Eccles et al., 1966). This particular synaptic relationship results from the withdrawal of supernumerary CFs during the first postnatal weeks (Crepel et al., 1976; Mariani et al., 1977; Mariani and Changeux, 1981a,b; Lohof et al., 1996; Hashimoto and Kano, 2005). During the period of synapse elimination, precise olivocerebellar connectivity is also achieved at the subcellular level with the translocation of CF terminals from sites on the PC somata to their final location on proximal dendrites. Around postnatal day 5 (P5) in the rat, when PCs have short immature den- 
drites, CFs make perisomatic contacts on the PCs, forming the somatic nest (Ramon y Cajal, 1911). Later, CF terminals move up the growing dendrites and reach the proximal dendritic compartment by $\mathrm{P} 10-$ P15 (Larramendi, 1969; Mason et al., 1990; Chedotal and Sotelo, 1993)

After unilateral transection of the olivo-cerebellar pathway (pedunculotomy) during the first postnatal week, the axotomized neurons of the inferior olive (IO) degenerate, and new axons arising from the unaffected IO grow through the cerebellar white matter into the denervated hemicerebellum and establish new synapses with PCs (Angaut et al., 1982; Sherrard et al., 1986; Zagrebelsky et al., 1997; Sugihara et al., 2003). During this early postnatal period, neosynaptogenesis involves a transient phase of multiinnervation, indicating that young PCs can be reinnervated by multiple CFs (Lohof et al., 2005). After this period of plasticity, no spontaneous reinnervation occurs (Sherrard et al., 1986) but it can be induced by the injection of neurotrophic factors (Sherrard and Bower, 2001, 2003).

In this study, we induced CF reinnervation with injections of BDNF into the denervated hemivermis of rats pedunculotomized at P15 (Dixon and Sherrard, 2006). Our results show that functional synapses form rapidly on the PC soma and thereafter translocate to the dendrites during the first week of reinnervation. These morphological events recapitulate the normal developmental pattern. However, multiple CF innervation does not occur, indicating that the PC has a determinant role in the control of synaptogenesis, particularly in selecting the number of $\mathrm{CF}$ afferents.

\section{Materials and Methods}

Animals and surgical procedures. Wistar rats were used according to the regulations of the Comité National d'Ethique pour les Sciences de la Vie et de la Santé, which are in accordance with the European Communities Council Directive (86/609/EEC). All surgical procedures were performed under diethylether (SDS) anesthesia. At $15 \mathrm{~d}$ postnatal, rats of either sex underwent unilateral transection of the left inferior cerebellar peduncle (pedunculotomy: Px15) as described previously (Bower and Waddington, 1981; Lohof et al., 2005). Some animals were sham operated: the knife was inserted in the fourth ventricle but not rotated, leaving the inferior peduncle intact. After $24 \mathrm{~h}$, recombinant human BDNF $(1 \mu \mathrm{l}$, 500-1000 ng/ $\mu$ l; Regeneron, Tarrytown, NY, or Alomone Laboratories, Jerusalem, Israel) was injected at 10-15 sites into lobules V-VIII of the left hemivermis to induce reinnervation of deafferented PCs as described by Sherrard and Bower (2001). Although lobules VI-VIII were targeted for the BDNF injection, the pipette enters the cerebellum at an angle, and other regions of the cerebellum (notably lobules IV-V) were sometimes injected. Vehicle (PBS, pH 7.3, with $0.1 \%$ bovine serum albumin) was injected in some pedunculotomized or sham-operated animals as controls. Animals were returned to the dam after surgical intervention. Successful pedunculotomies were assessed by gross inspection of the lesion
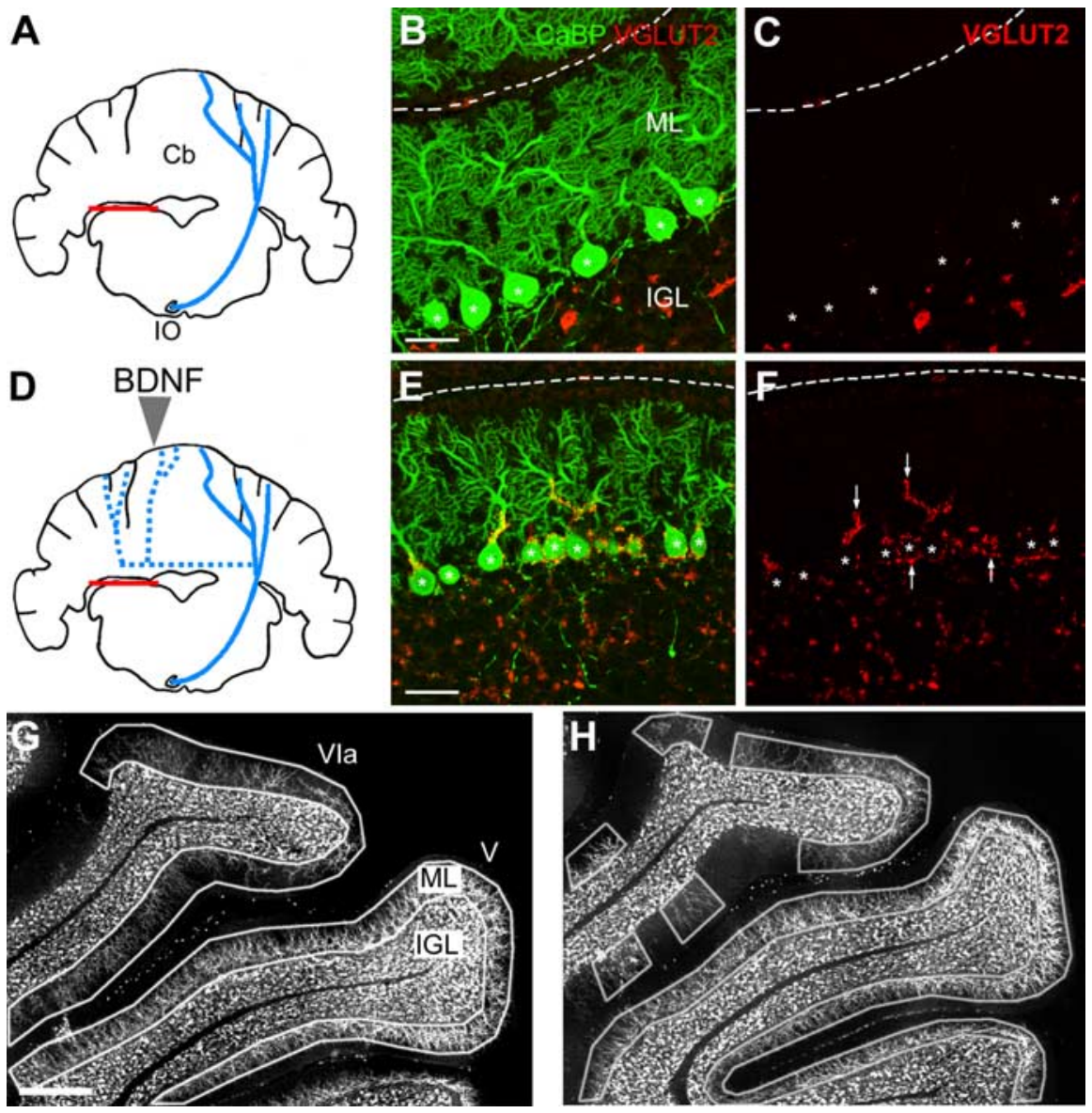

Figure 1. Time course of postlesional reinnervation. $\boldsymbol{A}-\boldsymbol{C}$, Rapid degeneration of lesioned CFs in the deafferented vermis. $\boldsymbol{A}$ Diagram illustrating the olivo-cerebellar projection after pedunculotomy at P15. Unilateral transection of the olivo-cerebellar 作 pedunculotomy at P15. CaBP-immunolabeled PCs (green) are not associated with VGLUT2 labeling either on their somata or on their dendrites. VGLUT2 labeling in the internal granular layer corresponds to mossy fibers. $\boldsymbol{D}-\boldsymbol{F}$, Postlesional reinnervation of $P C s$ in the deafferented vermis by transcommissural CFs. D, Diagram illustrating the development of the transcommissural path dashed line) after pedunculotomy at P15 and BDNF injection at P16. E, F, Confocal images, taken at P18, showing the appearance rows) contact somata (asterisks) and/or the proximal portion of dendrites from (aBP-immunolabeled PCs. G, $\boldsymbol{H}_{\text {, Images showing }}$ GLUT2 immunolabeling in lobules V-VI from the left vermis of Px15-BDNF rats (at P25) at $250 \mu \mathrm{m}(\boldsymbol{G})$ and $350 \mu \mathrm{m}(\boldsymbol{H})$ from the reinnervated regions. These patches are found primarily in or near the BDNF-injected lobules. Scale bars: $\boldsymbol{B}, \boldsymbol{C}, \boldsymbol{E}, \boldsymbol{F}, 80 \mu \mathrm{m} ; \boldsymbol{G}, \boldsymbol{H}$ $500 \mu \mathrm{m}$. ML, Molecular layer; IGL, internal granular layer.

when the rats were killed for electrophysiological or anatomical experiments.

For graft experiments, cerebellar primordia from 14-d-old Wistar rat embryos were dissected in PBS with $0.6 \%$ glucose, $\mathrm{pH} 7.3$. Grafts were injected into lobules VI-VIII of the left cerebellar vermis of P7 rats as described previously (Gardette et al., 1990). Pedunculotomy and BDNF injection were performed at P15 as described above. Grafted, lesioned, BDNF-injected animals were used for electrophysiology only if the pedunculotomy was complete and the graft was localized in the BDNFinjected region of the left hemivermis.

Immunohistochemistry and confocal microscopy. Immunocytochemical visualization of PC and CF terminals was done $2 \mathrm{~d}$ postinjection (DPI) and 9 DPI in cerebellar cortex of pedunculotomized (Px15) or shamoperated rats given injections of either BDNF or vehicle. Under isofluorane anesthesia, operated rats were perfused transcardially with $4 \%$ paraformaldehyde in $0.1 \mathrm{~m}$ phosphate buffer (PB), $\mathrm{pH}$ 7.3. The brains were removed and postfixed in the same fixative at $4^{\circ} \mathrm{C}$ overnight. Parasagittal sections ( $50 \mu \mathrm{m}$ thick) were cut from the left and right vermis ( 1 $\mathrm{mm}$ on either side of the midline) using a vibrating microtome 
Table 1. CF translocation from soma to proximal dendrites during late postnatal reinnervation

\begin{tabular}{llll}
\hline Age & Condition & Percentage of PCs with somatic CF innervation & CF extent (\% of the dendritic tree) \\
\hline 2 DPI (P18) & Reinnervated hemivermis & $84.4(n=501 ; N=4)^{*}$ & $26.0 \pm 1.6(N=5)^{* *}$ \\
& Right hemivermis & $25.0(n=640 ; N=4)$ & $51.9 \pm 0.6(N=5)$ \\
& Control vermis & $25.7(n=587 ; N=5)$ & $59.1 \pm 1.0(N=5)$ \\
9DPI (P25) & Reinnervated hemivermis & $20.8(n=307 ; N=5)$ & $66.5 \pm 0.9(N=5)$ \\
& Right hemivermis & $26.3(n=788 ; N=5)$ & $72.1 \pm 0.9(N=5)$ \\
& Control vermis & $23.0(n=792 ; N=5)$ & $68.5 \pm 2.4(N=5)$ \\
\hline
\end{tabular}

Data are expressed as mean \pm SEM. ${ }^{*} p<0.0001$ ( $\chi^{2}$ test); ${ }^{* *} p<0.0001$ (ANOVA and Scheffé's post hoc tests). $n$, Number of cells; $N$, number of animals.
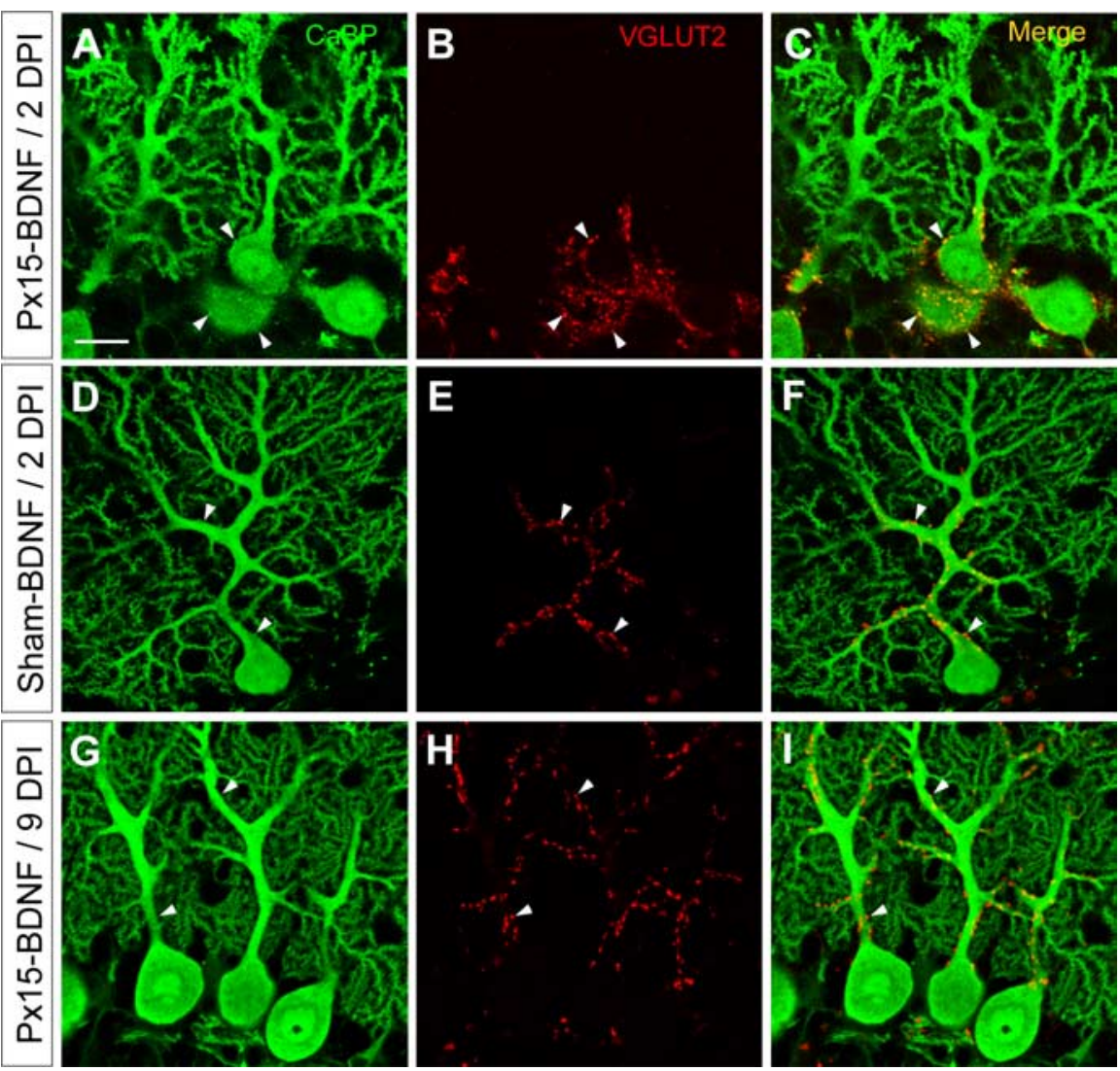

Figure 2. Morphological characteristics of the late postnatal reinnervation process. $\boldsymbol{A}-\boldsymbol{C}$, Confocal images of reinnervated cerebellar cortex at $2 \mathrm{DPI}$ (P18). Arrowheads indicate the location of VGLUT2-positive (F terminals (red) around the soma of the PC labeled for calbindin (green). D-F, In a control cerebellar cortex from a sham-operated BDNF-injected rat (P18), double labeling for calbindin and VGLUT2 shows the normal location of (F terminals on primary and secondary dendrites (arrowheads). $\boldsymbol{G}, \boldsymbol{H}$, At 9 DPI (P25), reinnervating CF terminals contact primary and secondary PC dendrites (arrowheads) in the reinnervated left hemivermis from Px15 and BDNF-injected animals, illustrating the normal final targeting of new CFs onto deafferented PCs. Scale bar, $40 \mu \mathrm{m}$.

(VT1000S; Leica, Vienna, Austria) and collected in 0.1 M PBS, pH 7.3. Nonspecific sites were saturated for $1 \mathrm{~h}$ in PBS containing $0.02 \%$ gelatin, $0.25 \%$ Triton X-100, and $0.1 \mathrm{~m}$ lysine in PBS (PBS-GTL), pH 7.3. The sections were then incubated overnight at $4{ }^{\circ} \mathrm{C}$ in a mixture of polyclonal guinea pig (GP) anti-vesicular glutamate transporter 2 (VGLUT2) antiserum (1:3000; Chemicon, Temecula, CA) and polyclonal rabbit anticalbindin D-28K (CaBP) antiserum (1:5000; Swant, Bellinzona, Switzerland) in PBS-GTL, pH 7.3. VGLUT2 is expressed by both cerebellar mossy fibers and CFs in the internal granule cell layer, but VGLUT2 is specific for CFs in the molecular layer (Fremeau et al., 2001). Calbindin is a specific marker for cerebellar PCs (Celio, 1990). After incubation with the primary antibodies, sections were rinsed in PBS and incubated for $2 \mathrm{~h}$ in a mixture of Cy3-conjugated donkey anti-GP IgG and FITCconjugated donkey anti-rabbit (each at 1:200 dilution; Jackson ImmunoResearch, West Grove, PA) in PBS-GTL, pH 7.3. Omitting the primary antibody eliminated the corresponding pattern of labeling. Sections were mounted in Mowiol (Calbiochem, La Jolla, CA) and examined using either standard fluorescence microscopy (Eclipse E800; Nikon, Tokyo, Japan) or an inverted confocal microscope (DM IRBE; Leica)

Morphological analysis. To quantify somatic versus dendritic innervation by CFs, vibratome sections were double immunolabeled for $\mathrm{CaBP}$ and VGLUT2, and fluorescence images were taken with a standard microscope equipped with a CCD camera (DFC 300FX; Leica). Only PCs with both the soma and the dendritic tree visible were taken into account to define subcellular CF localization: PCs were classed into groups with or without somatic CF contacts. We considered that a somatic interaction existed when at least four VGLUT2-positive varicosities were visible on the soma surface. Some sections were observed using confocal microscopy to allow more detailed characterization of these somatic and dendritic contacts.

In a second series of measurements on these same vibratome sections, we estimated $\mathrm{CF}$ translocation onto PC dendritic trees using ImageJ (National Institutes of Health, Bethesda MD) software to analyze images of histological sections immunolabeled for CaBP and VGLUT2. We defined rectangular areas corresponding to (1) the depth of the molecular layer occupied by PC dendritic trees and (2) the corresponding depth also occupied by VGLUT2-positive CF arbors. The ratio of these two areas provides an index of the CF extent on the dendritic tree.

Immunoelectron microscopy. Anesthetized Px15-BDNF and control (sham-operated, given injections of either BDNF or vehicle) rats (100 mg/kg ketamine, $5 \mathrm{mg} / \mathrm{kg}$ xylazine) were perfused transcardially at 2-3 DPI with a mixture of $4 \%$ paraformaldehyde and $0.5 \%$ glutaraldehyde in $0.1 \mathrm{M} \mathrm{PB}, \mathrm{pH} 7.3$. Brains were postfixed by immersion in $4 \%$ paraformaldehyde overnight at $4^{\circ} \mathrm{C}$. Parasagittal sections $(50 \mu \mathrm{m}$ thick) were cut using a vibrating microtome (VT1000S; Leica) and collected in PBS, pH 7.3. Plasma membranes were permeabilized either by $30 \mathrm{~min}$ incubation in a solution containing $0.05 \%$ Triton X-100 or by three freeze/thaw cycles in liquid nitrogen after cryoprotection in $20 \%$ sucrose and 20\% glycerol in PBS for $1 \mathrm{~h}$. After rinsing in PBS, nonspecific binding was blocked for $1 \mathrm{~h}$ with $0.02 \%$ gelatin and $0.1 \mathrm{M}$ lysine in PBS (PBS-GL), pH 7.3. Sections were incubated overnight at $4^{\circ} \mathrm{C}$ in PBS-GL containing polyclonal GP anti-VGLUT2 antiserum (1:3000; Chemicon). Sections were subsequently rinsed in PBS, incubated with donkey biotinconjugated anti-GP IgG (1:200; Chemicon) for $2 \mathrm{~h}$, and incubated with avidin-biotin peroxidase complex (Elite ABC kit; Vector Laboratories Burlingame, CA) for $30 \mathrm{~min}$. Finally, immunoreactivity was visualized with $\mathrm{DAB}(0.5 \mathrm{mg} / \mathrm{ml})$ and hydrogen peroxide $(0.03 \%)$. Sections were observed under light microscopy, and reinnervated regions were dissected out. These dissected blocks were then postfixed in $2 \%$ glutaraldehyde in $0.1 \mathrm{M} \mathrm{PB}$ for $10 \mathrm{~min}$ and then in $1 \% \mathrm{OsO}_{4}$ in $0.1 \mathrm{M} \mathrm{PB}$ for $30 \mathrm{~min}$ at room temperature. After dehydration in a graded ethanol series and treatment with propylene oxide, the blocks were embedded in Araldite. Ultrathin sections $(50 \mathrm{~nm})$ were cut with an ultramicrotome (Ultracut Reichert, Vienna, Austria), stained with 2\% uranyl acetate in 50\% ethanol, and finally examined with a transmission electron microscope (H7500; Hitachi, Tokyo, Japan) equipped with a digital camera (Ad- 
vanced Microscopy Techniques, Danvers, MA). PC profiles were easily identifiable based on ultrastructural criteria (Larramendi and Victor, 1967; Larramendi, 1969; Palay and Chan-Palay, 1974; Altman and Bayer, 1997). CFs were identified by their morphology and by the presence of a $\mathrm{DAB}$ reaction product.

Electrophysiology. Cerebellar parasagittal slices (200 $\mu \mathrm{m}$ thick) from the left hemivermis were prepared as described previously (Llano et al., 1991) from normal and pedunculotomized/BDNF-injected rats between 2 and 6 DPI and from grafted, pedunculotomixed, and BDNF-injected rats between 2 and 4 DPI. We recorded from PCs in the same region of the cerebellar vermis (within $1 \mathrm{~mm}$ from the midline) as the anatomical studies because it is consistently reinnervated (Dixon and Sherrard, 2006). We made whole-cell patch-clamp recordings from PCs using an upright microscope (BX50WI; Olympus France, Rungis, France) at $20^{\circ} \mathrm{C}$. Resistance of patch pipettes was 3-6 $\mathrm{M} \Omega$ when filled with a solution containing (in mM) $120 \mathrm{Cs}$ D-gluconate, 13 biocytin, 10 HEPES, 10 BAPTA, 3 TEACl, $2 \mathrm{Na}_{2}$ ATP, 2 MgATP, and 0.2 NaGTP, pH 7.3, 290$300 \mathrm{mOsm}$. Slices were perfused continuously with a bath solution containing (in mM) $125 \mathrm{NaCl}, 2.5 \mathrm{KCl}, 1.25 \mathrm{NaH}_{2} \mathrm{PO}_{4}, 26 \mathrm{NaHCO}_{3}, 2 \mathrm{CaCl}_{2}$, $1 \mathrm{MgCl}_{2}$, and 25 glucose and bubbled with $95 \% \mathrm{O}_{2}$ and $5 \% \mathrm{CO}_{2}$. Picrotoxin $(100 \mu \mathrm{M})$ was added to block inhibitory currents. Ionic currents were recorded from PCs using an Axopatch 200B amplifier (Molecular Devices, Foster City, CA). We used Acquis 1 and Elphy (Biologic, Grenoble, France) for data acquisition and analysis, respectively. CFEPSCs were elicited by stimulation in the internal granular layer with a saline-filled glass pipette. Duration and amplitude of stimulation were $0.1 \mathrm{~ms}$ and $1-100 \mathrm{~V}$, respectively. We distinguished CF-EPSCs from currents mediated by parallel fibers (PF-EPSCs) by their all-or-none character and by the demonstration of paired-pulse depression (Konnerth et al., 1990). In PCs where CF-EPSCs were successfully recorded at $-70 \mathrm{mV}$, we subsequently depolarized the PC to $0 \mathrm{mV}$ to prevent voltage-clamp escape of the $\mathrm{CF}$ current. This allowed us to more easily determine whether there were one or two CFs contributing to the EPSC. Series resistance was not compensated. To determine the number of CFs innervating a PC, we counted the number of discrete CF-EPSC steps that appeared when the intensity of stimulation was gradually increased or when the position of the stimulation electrode was changed.

After electrophysiological recording, slices were fixed in $4 \%$ paraformaldehyde, the recorded (biocytin-filled) PCs were visualized using fluorescent avidin (AF350; Invitrogen, Cergy-Pontoise, France), and the slices were processed for VGLUT2 immunohistochemistry (see above) to determine the reinnervated regions of the slice and allow comparison with the locations of the recorded PCs.

Digital images. Digital photomicrographs and electron micrographs were stored using Leica confocal software (for confocal microscopy) and Advanced Microscopy Techniques software (for electron microscopy). Adobe Photoshop 6 (Adobe Systems, Mountain View, CA) was used to make color montages and for final adjustment of contrast and brightness in all pictures.

Statistical analysis. ANOVA and Scheffé's post hoc tests were used to compare the extent of CF territory in the area occupied by PC dendritic trees from Px15 and sham-operated rats given injections of either BDNF or vehicle.

The $\chi^{2}$ test was used for all other comparisons: (1) to compare CF subcellular localization on PCs from Px15 rats and sham-operated rats given injections of either BDNF or vehicle; (2) to compare the number of CFs innervating PCs in normal rats with the number of CFs per reinnervated PC in Px15 rats given injections of BDNF; and (3) to compare the number of CFs per reinnervated PC from the host with the number of CFs per grafted PC.

\section{Results}

\section{Transcommissural CFs rapidly invade the denervated} left hemicerebellum

The course of PC reinnervation by CFs was investigated morphologically through immunofluorescence labeling of the VGLUT2. This antigen is specifically expressed by CF varicosities in the
A

P18

B

P25
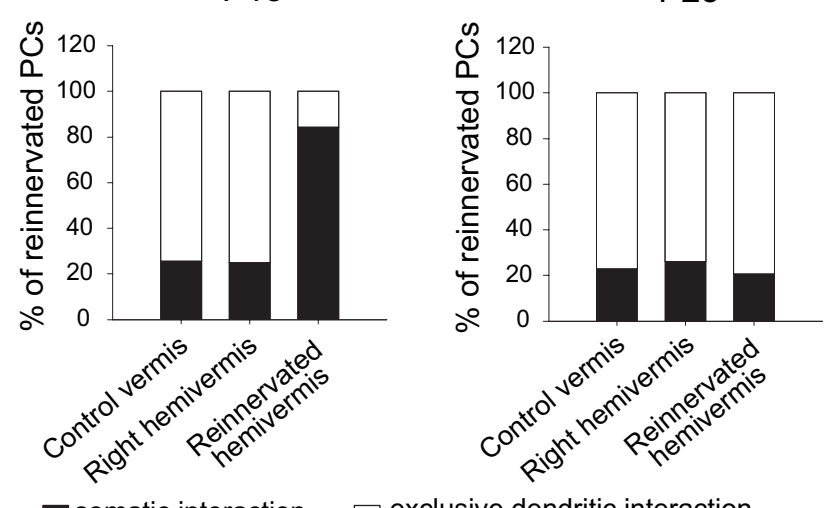

somatic interaction

C

P18

D
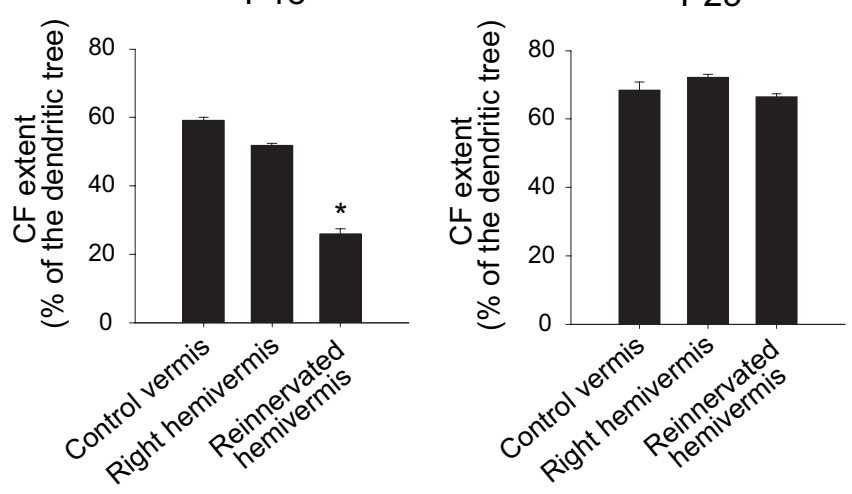

Figure 3. CF translocation from soma to proximal dendrites during late postnatal reinnervation. $\boldsymbol{A}, \boldsymbol{B}$, Percentage of $\mathrm{PC}$ s displaying a somatic interaction with VGLUT2-positive (F terminals at $2 \mathrm{DPI}(\mathrm{P} 18)(\boldsymbol{A})$ and $9 \mathrm{DPI}(\mathrm{P} 25)(\boldsymbol{B})$ from right hemivermis, reinnervated left hemivermis, and vermis from control animals (sham-operated BDNF or PBS injected). $C, D, C$ translocation, expressed as the percentage of depth of the $P C$ dendritic tree through which CFs extend (see Materials and Methods, Morphological analysis) at 2 DPI (P18) (C) and 9 DPI (P25) (D), from right hemivermis, reinnervated left hemivermis, and vermis from control animals. Error bars show SEM. * $p<0.0001$ (ANOVA and Scheffé's post hoc test).

molecular layer of the cerebellar cortex (Fremeau et al., 2001; Ichikawa et al., 2002; Miyazaki et al., 2003).

Forty-eight hours after pedunculotomy and $24 \mathrm{~h}$ after vehicle injections (P17), no CFs were observed in the molecular layer of the left hemivermis (two animals) (Fig. $1 A-C$ ). This rapid degeneration is similar to previous observations (Sotelo et al., 1975; Anderson and Flumerfelt, 1980; Cesa et al., 2005). In Px15 animals given injections of BDNF, VGLUT2-labeled CFs were observed in the molecular layer of the left hemivermis as early as 2 DPI (Fig. $1 D-F$ ). The new CF branches formed patches of reinnervation, separated by non-reinnervated regions (Fig. 1G,H).

\section{Transcommissural reinnervating CFs form transient synapses} on PC somata

\section{Morphological analysis of reinnervation}

We wanted to see whether the process of reinnervation recapitulated normal development, that is, whether the CFs initially innervated the soma or passed directly to the proximal dendrites, which are the synaptic sites appropriate for this stage of development. We examined the pattern of targeting (somatic vs dendritic) by reinnervating CFs in the left hemivermis within $1 \mathrm{~mm}$ from the midline, where the most extensive reinnervation occurs.

At 2 DPI (P18), in the left hemivermis, CFs closely surrounded 


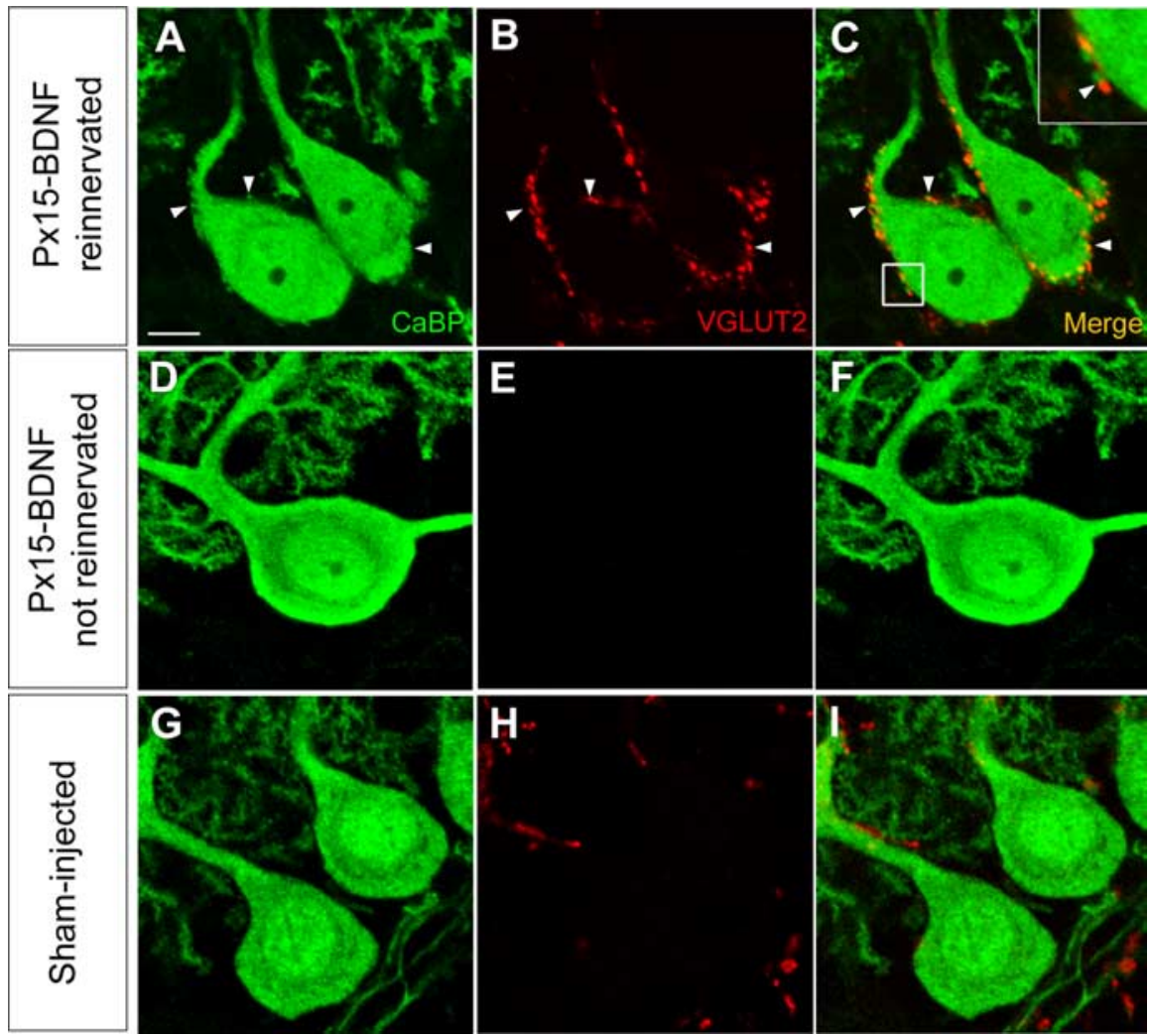

Figure 4. VGLUT2-positive CFs contact somatic thorns during late postnatal reinnervation. $\boldsymbol{A}-\boldsymbol{C}$, Double labeling for $\mathrm{CaBP}$ (green) and VGLUT2 (red). Arrowheads indicate somatic thorns from reinnervated PCs at 2 DPI, associated with VGLUT2-positive CF terminals. D-F, Soma from a non-reinnervated PC at 2 DPI. No VGLUT2-positive CF terminals are visible, and the PC soma displays a smooth surface lacking somatic thorns. $\mathbf{G}, \boldsymbol{H}, \mathrm{PC}$ somata from sham-injected rats at P18. No VGLUT2-positive CF terminals are visible on the somatic surface, and PCs have no somatic thorns. Scale bar, $10 \mu \mathrm{m}$.

the soma of most reinnervated PCs (Table 1; Figs. 2A-C, $3 A$ ). Somatic CF contacts were much less frequent in the right vermis and in the vermis of control rats (sham operated, given injections of BDNF or vehicle) at the same age (Figs. $2 D-F, 3 A$ ). In cases in which the new CFs contacted the dendrites, they formed immature arborizations over the proximal portion of the dendritic tree. In contrast, in the right hemivermis or the vermis of control animals, arbors ramified over a more extensive portion of each dendritic tree (Table 1, Fig. 3C).

Closer examination of the sites of transient CF contacts on the soma and basal part of the primary dendrite at $2 \mathrm{DPI}$ revealed that CF varicosities were apposed to short somatic thorns that were exclusively encountered on reinnervated PCs (Fig. 4A-C). Importantly, somatic protrusions were not observed on nonreinnervated PC somata (Fig. $4 D-F$ ), on PCs in the right (unaffected) hemivermis, or in control animals (Fig. $4 G-I$ ), suggesting that these thorns develop after arrival of new CFs and/or in response to them.

At 9 DPI (P25), most of the reinnervated PCs displayed CF innervation exclusively on proximal dendrites, with some also showing somatic contacts (Table 1; Figs. $2 G-I, 3 B$ ). This localization is not different from that in the right hemivermis or from that in vermis of control animals. Also at this age, reinnervating CF arborizations have a mature localization, extending over twothirds of the depth of the molecular layer occupied by PC dendritic trees, which is similar to the right hemivermis and the vermis of control rats (Table 1, Fig. 3D).

These observations demonstrate that proximal dendrites remain the ultimate subcellular target of CFs during late reinner- vation. In our model, this dendritic targeting occurs after a transient interaction with the soma, suggesting that reinnervating CFs in this model may follow cellular targeting signals similar to those that are present during development.

\section{Ultrastructural characteristics of initial CF-PC synapses}

To clarify whether these early contacts made by CFs on PC somata were, in fact, potentially functional synapses as opposed to growth cones growing past the soma toward the dendrites, we examined the initial interaction between new CFs and PCs at the ultrastructural level at 2-3 DPI. In electron micrographs, VGLUT2labeled CF varicosities were found apposed to the PC soma and the proximal dendritic trunk, confirming the existence of a CF mesh around the basal part of the PC. In control animals at the same age, CF terminals were extremely rare in this region.

The reinnervating CF terminals displayed features typical of normal CFs boutons, comparable to controls of the same age: they were filled with a few mitochondria scattered among densely packed round vesicles (Fig. 5). Large dense-core vesicles were seen occasionally. Intervaricose profiles contained a few vesicles distributed along microtubules.

Vesicle-rich terminal CF boutons established asymmetric synaptic contacts onto the soma and proximal dendrites of the PCs. In all CF-PC asymmetric synapses observed, VGLUT2 immunoperoxidase reaction product intensely stained the presynaptic vesicles accumulated close to the active zone facing the corresponding postsynaptic density (Fig. 5A1,A2). CF synapses were occasionally established on the smooth membrane of the PC (Fig. $5 B$ ), but much more often on thorns emerging from the soma (Fig. $5 A, C, D$ ) or from proximal dendrites (Fig. $5 E$ ). These thorns were generally characterized by a short stalk ending in a rounded head (Fig. 5), thus resembling thorns encountered on the primary and secondary dendrites of control PCs (Larramendi and Victor, 1967). In both the reinnervated and control molecular layer, CFs boutons often made synapses with several surrounding dendritic thorns. Symmetric synapses (presumably inhibitory) as well as glial processes were observed on the PC soma in both control and experimental situations (data not shown).

Therefore, ultrastructural analysis demonstrates the formation of true synapses onto PC somatic thorns resembling those described during the developmental pericellular nest phase (Larramendi, 1969; Laxson and King, 1983). The reinnervation of PCs by CFs induced by intracerebellar BDNF injections after Px15 thus involves transient somatic innervation of well differentiated PCs (around P18), despite the presence of their ultimate dendritic targets, surrounding glial cells, and inhibitory presynaptic terminals of interneurons that are not present during developmental synaptogenesis (Altman, 1972; Palay and Chan-Palay, 1974; Altman and Bayer, 1997). 


\section{Direct establishment of a one-to-one synaptic relationship between transcommissural CFs and late postnatal PCs}

Because we saw that reinnervating CFs first synapsed onto the PC soma before translocating to the proximal dendrites, recapitulating the normal developmental process, we wanted to see whether multiple innervation and synapse elimination would also be repeated during reinnervation. The process of PC reinnervation by CFs was followed beginning at 2 DPI (P18), that is, when the lesioned CFs have completely degenerated and new transcommissural CFs begin to contact deafferented PCs. Between 2 and 6 DPI (P18-P22), CF responses were recorded from 79 of 153 PCs from 18 successfully pedunculotomized rats (Fig. $6 A 1, A 2)$. All reinnervated $\mathrm{PCs}$ were subsequently found to be located in regions of the slice with VGLUT2 immunostaining in the molecular layer. The percentage of PCs displaying CF-EPSCs in these VGLUT2positive regions was essentially stable (43$58 \%$ ) between 2 and 6 DPI but was less than in control animals (69-86\%) under the same experimental conditions (Table 2).

Importantly, recordings revealed that, rather than a transient multi-innervation, the new transcommissural CFs directly established a one-to-one relationship with PCs. Of the 79 innervated PCs, only 3 (3.8\%; found on days 3-5 DPI) displayed two discrete CF-EPSCs indicating a double innervation, whereas all others (96.2\%) were mono-innervated (Fig. 6B). These results do not differ from control PCs in normal rats during the same period (P18-P22): 3.1\% of 65 innervated PCs were double innervated; all others were mono-innervated (10 animals; $p>0.05$, $\chi^{2}$ test) (Fig. 6B).

These results indicate that postlesional reinnervation does not recapitulate all events of the developmental synaptogenesis. Although some aspects of the morphological interactions between the reinnervating CFs and their PC targets occur, there is not, in parallel, a repetition of the multiple innervation and synapse elimination phases characteristic of normal development.
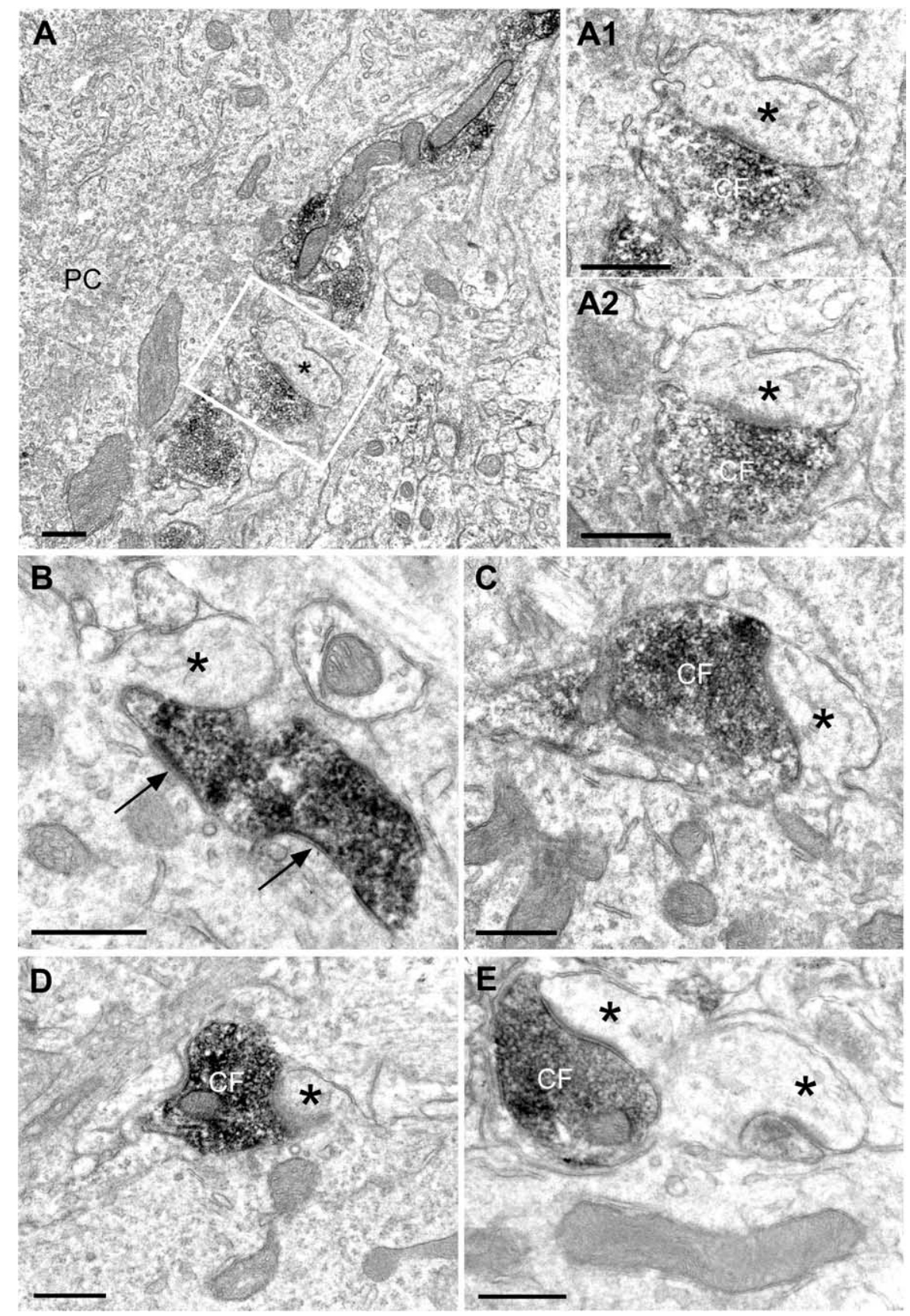

Figure 5. VGLUT2-positive CF terminals establish true synapses with somatic thorns. $\boldsymbol{A}-\boldsymbol{A 2}$, Immunoelectron micrographs showing a thorn (asterisk) that has grown on the surface of a reinnervated PC soma at 2 DPI. A, A VGLUT2-positive CF runs along the PC somatic membrane. $\boldsymbol{A}$ 1, $\boldsymbol{A}$, Higher magnifications at two different levels of the thorn framed in $\boldsymbol{A}$. A VGLUT2-positive CF varicosity establishes a true asymmetric synapse on the side of the thorn, identifiable by the accumulation of presynaptic vesicles facing a postsynaptic density. $\boldsymbol{B}$, A VGLUT2-positive varicosity contacting a thorn (asterisk) emerging from a reinnervated PC soma establishes an asymmetric synapse (arrows) with the smooth surface of the PC soma. C, D, Asymmetric synapses established by VGLUT2-positive (F varicosities on PC somatic thorns (asterisks). $\boldsymbol{E}$, Classical asymmetric synapses made by CF varicosities on a thorn (asterisk) of a PC dendrite in the basal molecular layer of the left hemivermis from a Px15-BDNF rat at 2 DPI. Scale bars, $500 \mathrm{~nm}$.

\section{The developmental stage of PCs controls the establishment of multi-innervation}

To differentiate the roles of PC maturation versus cerebellar microenvironment in the direct establishment of CF monoinnervation, we compared neosynaptogenesis of CFs onto immature grafted PCs (equivalent age, P4-P6) versus relatively mature host PCs (P18-P20) at the same date and in the same late postnatal extracellular environment. Thus, embryonic cerebellar pri- mordia were grafted into the cerebellum of rats aged P7 before pedunculotomy at P15 and BDNF injection at P16.

As described previously for grafts in adult animals (Gardette et al., 1990; Tempia et al., 1996), CaBP and VGLUT2 immunolabeling as well as electrophysiology showed that grafted PCs integrated into the host cerebellar cortex, usually in ectopic locations in the molecular layer and sometimes in the granular layer or the white matter depending on the injection site (Fig. 7). 
A1

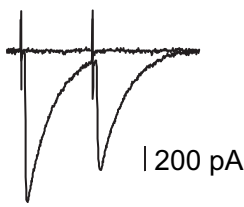

A2

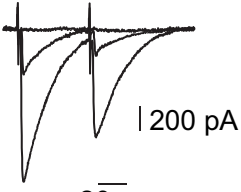

$2 \overline{\mathrm{ms}}$
B

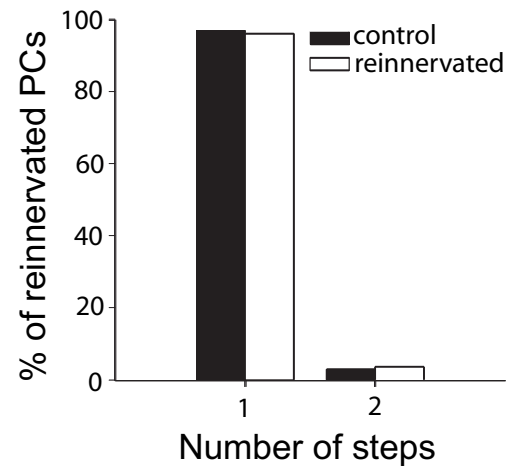

Figure 6. Direct establishment of mono-innervation between transcommissural CFs and reinnervated PCS. A1, A2, CF-EPSCs elicited by stimulation of transcommissural reinnervating CFs. A1, An example of a single-step CF-EPSC from a PC at 3 DPI (P19), reflecting monoinnervation. A2, An example of two-step CF-EPSCs illustrating double innervation from a PC at 4DPI (P20). The holding potential was $0 \mathrm{mV}$. B, Number of discrete steps in the (F-EPSC elicited in PCs from normal rats (filled bars) and Px15-BDNF rats (open bars) between 2 DPI (P18) and 6 DPI (P22).

Table 2. Percentage of CF-innervated PCs in VGLUT2-positive regions in control rats and in pedunculotomized rats given injections of $B D N F$

\begin{tabular}{lllll}
\hline \multirow{2}{*}{ Age } & Condition & $\begin{array}{l}\text { Percentage of CF-innervated PCs } \\
\text { in VGLUT2-positive regions }\end{array}$ & $n$ & $N$ \\
\hline 2 DPI (P18) & Reinnervated & $43.0 \pm 6.6$ & 20 & 3 \\
& Control & $72.5 \pm 2.5$ & 22 & 2 \\
3 DPI (P19) & Reinnervated & $47.3 \pm 3.1$ & 43 & 4 \\
& Control & $68.9 \pm 8.9$ & 14 & 2 \\
4 DPI (P20) & Reinnervated & $54.7 \pm 9.2$ & 33 & 4 \\
& Control & $85.6 \pm 7.2$ & 24 & 3 \\
5 DPI (P21) & Reinnervated & $58.2 \pm 10.6$ & 35 & 4 \\
& Control & $78.3 \pm 11.7$ & 24 & 3 \\
6DPI (P22) & Reinnervated & $52.2 \pm 7.8$ & 22 & 3 \\
& Control & $84.2 \pm 9.2$ & 29 & 4 \\
\hline
\end{tabular}

Data are expressed as mean \pm SEM. $n$, Number of cells; $N$, number of animals.

In grafted control animals at P18, grafted PCs (equivalent age, P5) were easily identifiable by the absence of well developed dendritic trees, in contrast to PCs from the host. VGLUT2 immunolabeling revealed the presence of glutamatergic terminals onto grafted PCs, suggesting innervation. In addition, at this date, patch-clamp recordings showed that grafted PCs were indeed innervated by CFs (data not shown). We then performed pedunculotomy at P15 and injections of BDNF at P16 using grafted animals. Recordings from grafted PCs and host PCs were made from eight successfully grafted and pedunculotomized rats aged P18-P20 (Fig. 8). In agreement with our results from nongrafted animals after lesion and reinnervation, whole-cell patch-clamp recordings showed that $\mathrm{PCs}$ from the host were reinnervated by only one CF $(100 \% ; n=8)$. In contrast, $80 \%$ of neighboring CF-innervated grafted PCs were multi-innervated with a mean $( \pm \mathrm{SEM})$ of $2.1 \pm 0.2 \mathrm{CFs}$ per PC $\left(n=15 ; p<0.05, \chi^{2}\right.$ test $)$ regardless of their location in the molecular layer $(n=5$, with four multi-innervated), granule cell layer ( $n=7$, with five multiinnervated), or white matter ( $n=3$, all multi-innervated).

These results demonstrate that, in the same extracellular (host) environment, immature PCs are multi-innervated by ingrowing CFs, whereas PCs at a later stage of their maturation are directly mono-innervated.
A
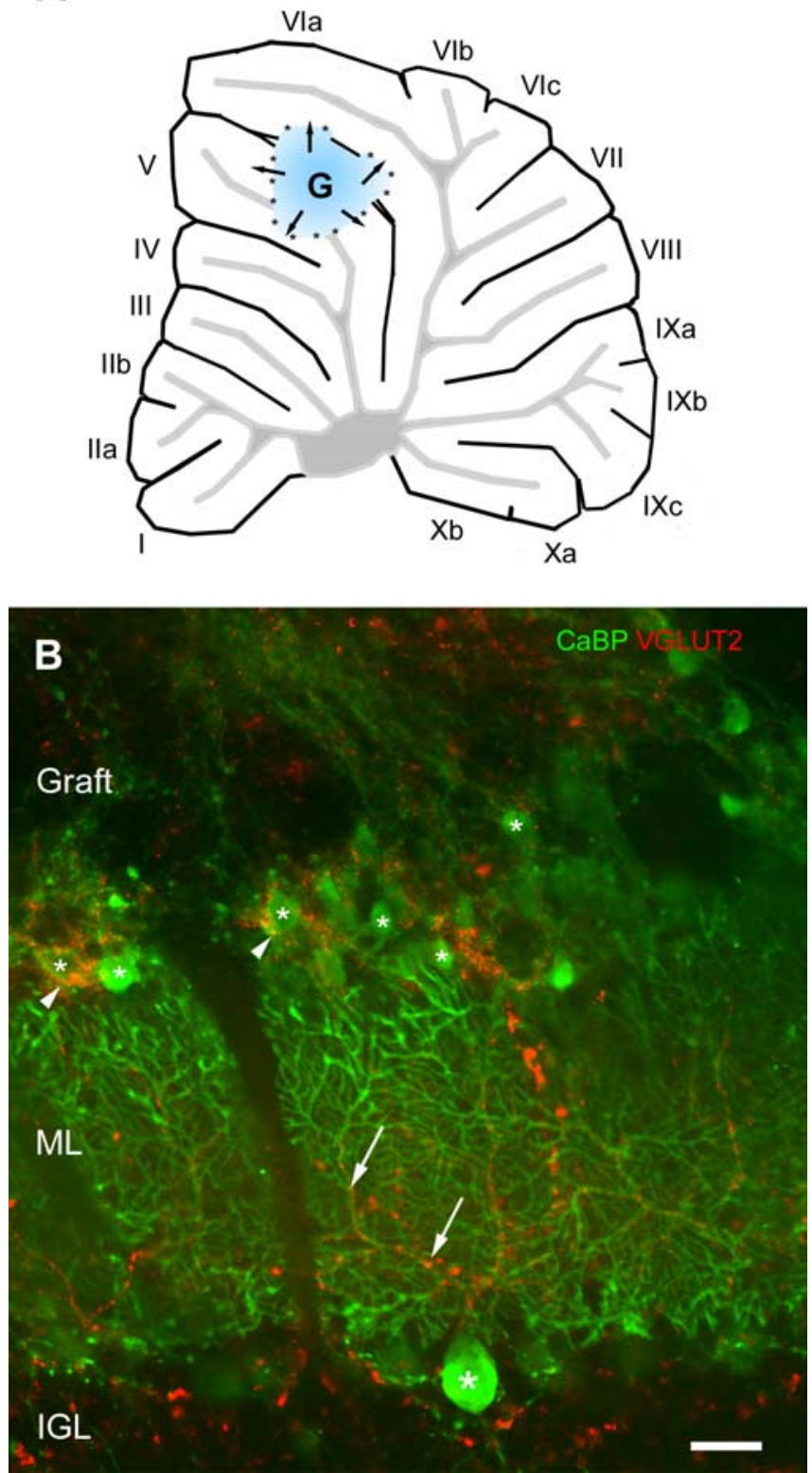

Figure 7. Immature grafted PCs integrate into the host cerebellar cortex. $\boldsymbol{A}, \mathrm{A}$ schematic diagram showing the position of the graft $(G)$ in one experimental animal. $\boldsymbol{B}$, Immunohistochemistry showing the integration of grafted PCS, which appear to migrate from the graft (top of the image), into the molecular layer (ML) of the host cerebellar cortex (P19). VGLUT2-positive CFs (red) contact both the host PCs (arrows) and the immature grafted PCs (arrowheads). Both PC populations are CaBP positive (green; see asterisks). IGL, Internal granule cell layer. Scale bar, $30 \mu \mathrm{m}$

\section{Discussion}

In this study, we investigated the effect of target maturation on afferent-target interaction, using electrophysiological and morphological characteristics of postlesional CF-PC neosynaptogenesis at a relatively late stage of PC maturation. Our results suggest an important role of postsynaptic PC maturation in regulating the number of CF afferents.

\section{CFs make transient axo-somatic synapses on PCs before} innervating proximal dendrites

During postlesional reinnervation, new CF afferents transiently contact the PC somata, establishing functional synapses. Ultra- 

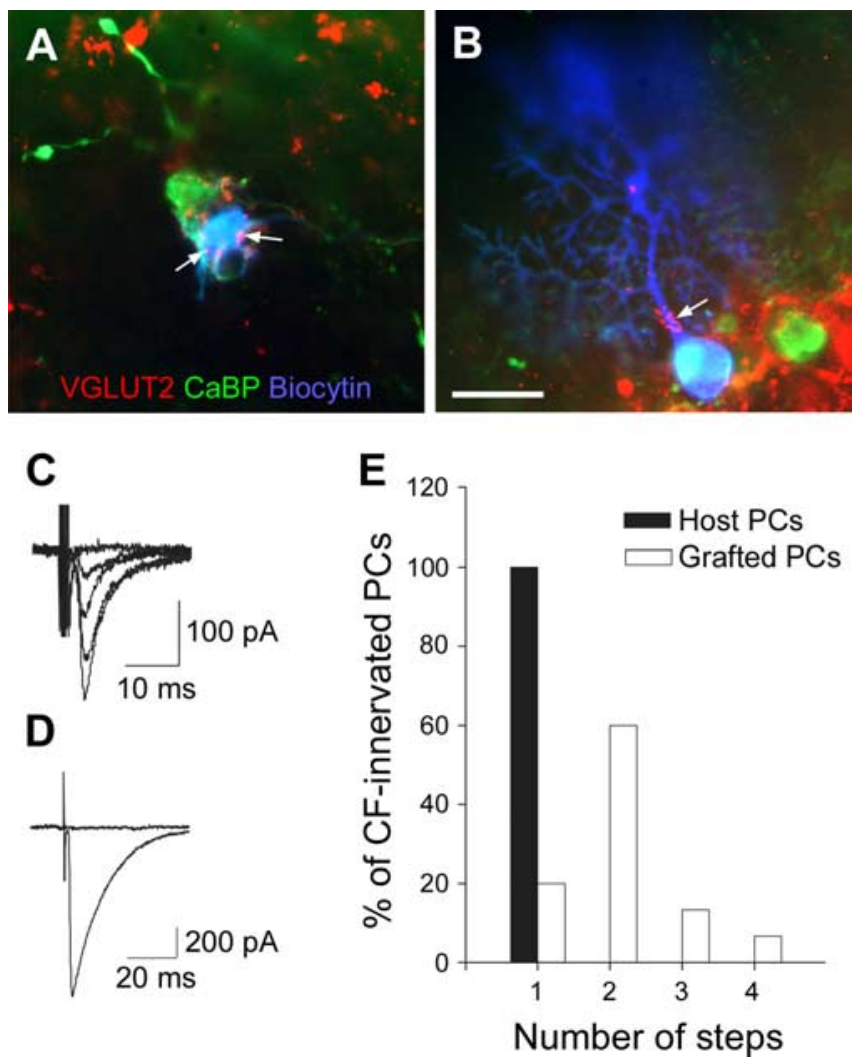

Figure 8. $\quad P C$ maturation determines multiple or single CF innervation. Immunohistochemistry and electrophysiology of grafted $(\boldsymbol{A}, \boldsymbol{C})$ and host $(\boldsymbol{B}, \boldsymbol{D}) \mathrm{PC}$ are shown. $\boldsymbol{A}, \boldsymbol{B}$, Triple labeling for CaBP (green), VGLUT2 (red), and biocytin (blue, indicating the recorded PC). Arrows indicate sites of contact between VGLUT2-positive (F terminals and grafted $(\boldsymbol{A} ; \mathrm{P} 19)$ or host $(\boldsymbol{B} ; \mathrm{P} 20)$ PCs. Scale bar, $30 \mu \mathrm{m}$. $\boldsymbol{C}, \boldsymbol{D}$, Electrophysiological recordings of $($ Fs from grafted $(\boldsymbol{C})$ and host $(\boldsymbol{D}) \mathrm{PC}$ after pedunculotomy and BDNF-induced reinnervation. $\boldsymbol{E}$, Histogram showing the numbers of CFs innervating host and grafted PCs.

structural analysis revealed that early somatic CF contacts are asymmetric synapses, usually made on perisomatic thorns. At this age, the perisomatic thorns, which resemble those seen during normal development (Larramendi, 1969; Laxson and King, 1983), are specifically found on reinnervated PCs (and not on CF-free PCs in the same animal or on PCs from control animals) and are systematically associated with a CF terminal. This effect is reminiscent of the clustering of target cell filopodia in response to the arrival of the innervating axon in the Drosophila neuromuscular system (Ritzenthaler et al., 2000) and afferent induction of spines in cultured neurons (Segal et al., 2003; Kossel et al., 1997). Thus, in contrast with the genesis of PF-innervated branchlet spines, which occurs later after CF denervation (3-5 d) (Cesa et al., 2005) and seems to be PC autonomous (Sotelo, 2004; Yuste and Bonhoeffer, 2004), this result suggests that the emergence of somatic thorns is induced by CF arrival. Although we cannot exclude a permissive role for BDNF, it appears to have no direct effect on the emergence of these somatic thorns.

At the end of the reinnervation process, somatic CF innervation has been primarily replaced by innervation on the proximal dendrites, demonstrating that the somatic interaction is transient. Thus, late postnatal reinnervation in our model recapitulates some aspects of CF innervation present during development, suggesting that the mechanisms underlying the $\mathrm{CF}$ subcellular targeting from the soma to proximal dendrites during development are also available during late reinnervation. The molecular mechanisms underlying this translocation are un- known but may be similar to the changes in subcellular targeting of the basket cell axons on PCs, which depends on a subcellular gradient of a cell adhesion molecule (Ango et al., 2004).

It is interesting to compare our experimental model with a different system of reinnervation that involves local sprouting rather than transcommissural axonal growth. Rossi et al. (1991a,b) made partial olivary lesions in adult animals by injection of the toxin 3-acetylpyridine. Surviving CFs sprout within $3 \mathrm{~d}$ after the lesion and grow locally in the molecular layer to innervate neighboring denervated PCs. Contacts are generally first made directly on dendrites in the molecular layer, but later the CF can also grow downward to contact the PC soma. Therefore, in this situation, somatic innervation is not a preliminary step preceding CF innervation of the dendrite. This could be attributable to the fact that the reinnervating CFs are not new transcommissural axons growing through the white matter into the target field but rather are local sprouts from CFs innervating the dendritic compartment of neighboring PCs. Thus, reinnervating CFs contact first the soma or the dendrite depending on the model, but in both cases, the dendrites are the main final subcellular target.

PC maturation regulates the number of reinnervating CFs: direct mono-innervation of late postnatal PCs

During postlesional reinnervation of a $\mathrm{PC}$ after the end of normal CF regression, only one CF synapses on each PC, a status that is appropriate for the developmental state of the PC. The absence of transient multi-innervation does not impair the ultimate dendritic targeting of reinnervating CFs, consistent with previous studies showing that CF translocation and CF elimination are independent events (Mariani, 1983; Scelfo et al., 2003).

It is unlikely that the mono-innervation we observed is attributable to an insufficient number of transcommissural axons in the denervated cerebellum for several reasons. First, we did record double-step CF-EPSCs in a few reinnervated PCs, at the same frequency as in control animals at this age $(\sim 4 \%)$, suggesting double innervation of these cells. Second, in reinnervated regions, $43-58 \%$ of $\mathrm{PCs}$ were innervated by a CF; this rate of reinnervation is similar to that found in some cases during the first few days after pedunculotomy at P3 or P5, but those PCs are almost always multiply innervated (A. M. Lohof, unpublished results). Finally, our experiments in which grafted immature PCs integrate into the host cerebellum before pedunculotomy and reinnervation show that these immature PCs, whether located in the molecular layer, the granule cell layer, or the folial white matter, undergo multiple CF innervation, whereas more mature PCs from the host animal are mono-reinnervated (Fig. 8). Thus, in the presence of a number of olivary axons compatible with multi-innervation, late postnatal PCs are nonetheless mono-innervated.

In addition, these graft experiments indicate that excess BDNF does not directly affect whether a PC is mono-innervated or multi-innervated, because immature (grafted) PCs undergo multi-innervation, whereas mature (host) PCs exposed to the same excess BDNF are mono-reinnervated. In many other experimental models, variations in the levels of neurotrophin signaling alters processes as diverse as growth cone motility (Moon and Gomez, 2006), axonal extension and competition (Singh and Miller, 2005), and refinement of projections (Cabelli et al., 1995). The specific effects of BDNF in our model are not known, but the excess BDNF does not appear to directly determine the number of CFs per PC.

Finally, it is unlikely that the substantial developmental 


\section{A Developmental synaptogenesis / Early post-natal neosynaptogenesis}
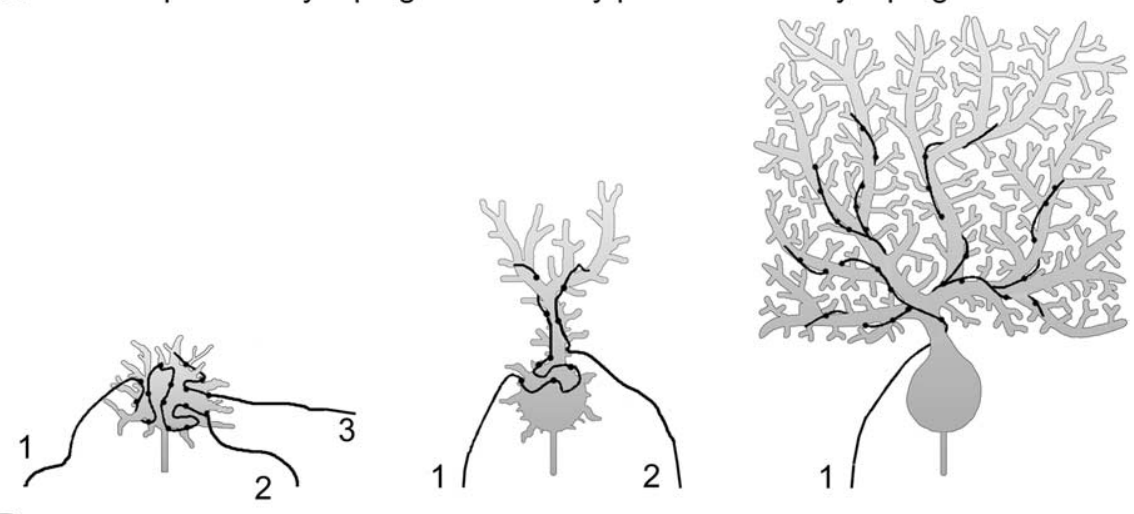

B

Late post-natal neosynaptogenesis
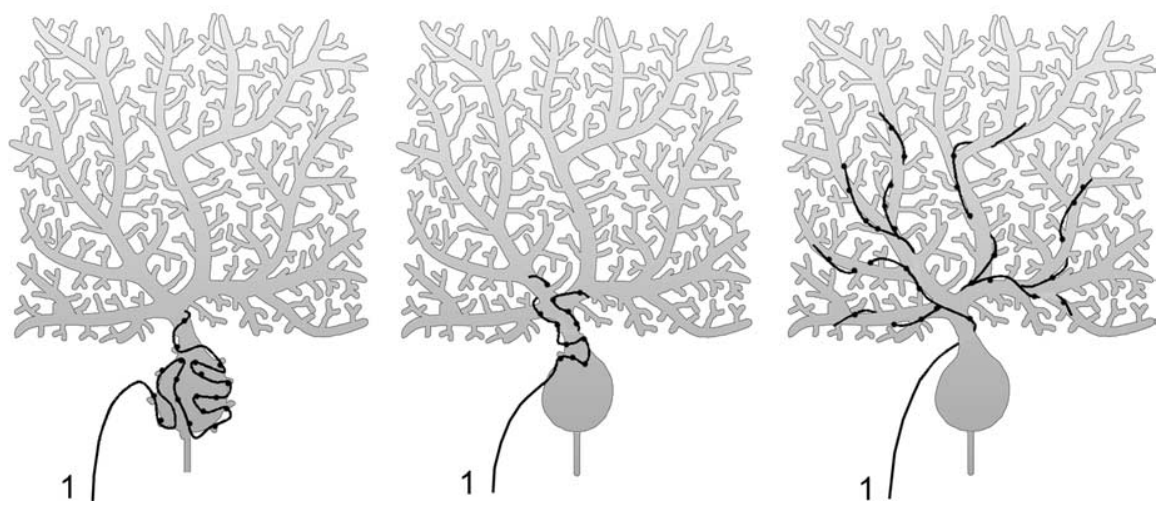

Figure 9. Different processes of CF-PC synaptogenesis in the rat olivo-cerebellar system. $A$, Developmental CF-PC synaptogenesis and early postnatal neosynaptogenesis are characterized by transient multi-innervation and translocation of CFs terminals from the soma to the dendrites as the PCs are elaborating their dendritic trees. $\boldsymbol{B}$, Late postnatal neosynaptogenesis, in contrast, is characterized by the direct mono-innervation of PCs by reinnervating CFs. However, synapses are first formed on the soma, and CF terminals later translocate from the soma to dendrites to reach their normal localization. The numbers indicate the number of steps.

changes occurring in the environment of the PC control the number of $\mathrm{CF}$ afferents during reinnervation. A number of previous studies (Sotelo and Alvarado-Mallart, 1987; Gardette et al., 1990; Sotelo et al., 1990; Rossi et al., 1992, 1994) showed that grafted immature PCs integrate into the mature host cerebellum. These grafted PCs receive synaptic inputs from PFs, inhibitory interneurons, and CFs (Gardette et al., 1990; Sotelo et al., 1990; Tempia et al., 1996), and they interact with the host Bergman glia. Importantly, despite these close interactions with the mature host environment, grafted PCs undergo transient CF multiinnervation (Gardette et al., 1990; Tempia et al., 1996). In this regard, the direct mono-innervation of relatively mature PCs in our model, contrasting with the multi-innervation of grafted PCs in the same cerebellum, is more likely attributable to an effect of PC maturation than to the environment (Fig. 9). This is consistent with previous results showing that immature PCs can be multi-reinnervated during postlesional neosynaptogenesis (Lohof et al., 2005). In addition, Rabacchi et al. (1992b) showed that in the Lurcher mutant the PC is intrinsically unable to respond to the signals that normally trigger CF elimination, underlining that the target $\mathrm{PC}$ is an active participant in this process.

\section{Selective synapse stabilization and restriction of the number of CF afferents during late reinnervation}

The current view of developmental synapse elimination in the olivocerebellar system is that CFs compete for the target cell so that only one CF among several synaptic inputs is selected and strengthened until mono-innervation is achieved (Lohof et al., 1996; Hashimoto and Kano, 2003, 2005). Normal connectivity between PCs and granule cells is essential for the refinement of olivo-cerebellar connections (Mariani and Changeux, 1980; Mariani, 1982, 1983; Benoit et al., 1987; Mariani et al., 1990; Fuhrman et al., 1994; Fournier et al., 2002, 2005), and the late phase of the refinement requires neuronal activity (Rabacchi et al., 1992a; Kakizawa et al., 2000; Andjus et al., 2003).

The results we present here provide evidence for direct establishment of monoinnervation in the mature mammalian CNS, demonstrating that transient multiinnervation and synaptic exuberance are not a prerequisite for synaptic partners to reach the one-to-one relationship.

It is possible that the PC is modified during development so that multiple CFs can no longer form synaptic contacts. During normal innervation or reinnervation, then, a young PC will allow innervation by additional CFs over a period of several days (Mariani and Changeux, 1981a; Lohof et al., 2005). In contrast, the mature PC would respond to reinnervation by a first $\mathrm{CF}$ with signaling mechanisms that block additional CFs from innervating.

A second possibility is that maturation and/or developmental synapse elimination confers a cellular identity such that only a compatible $\mathrm{CF}$ can reinnervate a given PC. This implies that synaptic partners select each other through recognition mechanisms, a hypothesis consistent with recent cell-biological models (Jontes and Phillips, 2006) that aim to explain the generation of synaptic specificity by selective stabilization (Changeux and Danchin, 1976). It is proposed that specific complements of adhesion and recognition molecules specify contacts during the stabilization phase of synaptogenesis (Boulanger et al., 2001; Yamagata et al., 2003; Jontes and Phillips, 2006) and define a cellular identity that could affect late reinnervation. The maturation state of the $\mathrm{PC}$ would thus have a permissive effect on multi-innervation and multi-reinnervation early in development and favor CF mono-innervation and monoreinnervation later as synaptic development progresses.

\section{Conclusion}

The experiments described here show that the developmental stage of the postsynaptic $\mathrm{PC}$ is a critical factor in the control of the number of CF afferents. Although many morphological characteristics of developmental synaptogenesis are recapitulated when synapse formation is induced onto a mature PC, multiple innervation is not repeated, suggesting that this aspect of synaptic specificity is governed by the maturation of the postsynaptic cell.

\section{References}

Altman J (1972) Postnatal development of the cerebellar cortex in the rat. II. Phases in the maturation of Purkinje cells and of the molecular layer. J Comp Neurol 145:399-463. 
Altman J, Bayer SA (1997) Development of the cerebellar system in relation to its evolution, structure and functions. Boca Raton, FL: CRC.

Anderson WA, Flumerfelt BA (1980) A light and electron microscopic study of the effects of 3-acetylpyridine intoxication on the inferior olivary complex and cerebellar cortex. J Comp Neurol 190:157-174.

Andjus PR, Zhu L, Cesa R, Carulli D, Strata P (2003) A change in the pattern of activity affects the developmental regression of the Purkinje cell polyinnervation by climbing fibers in the rat cerebellum. Neuroscience 121:563-572.

Angaut P, Alvarado-Mallart RM, Sotelo C (1982) Ultrastructural evidence for compensatory sprouting of climbing and mossy afferents to the cerebellar hemisphere after ipsilateral pedunculotomy in the newborn rat. J Comp Neurol 205:101-111.

Ango F, di Cristo G, Higashiyama H, Bennett V, Wu P, Huang ZJ (2004) Ankyrin-based subcellular gradient of neurofascin, an immunoglobulin family protein, directs GABAergic innervation at Purkinje axon initial segment. Cell 119:257-272.

Benoit P, Mariani J, Delhaye-Bouchaud N, Chappuis G (1987) Evidence for a multiple innervation of cerebellar Purkinje cells by climbing fibers in adult ferrets infected at birth by a mink enteritis virus. Brain Res 431:51-57.

Boulanger LM, Huh GS, Shatz CJ (2001) Neuronal plasticity and cellular immunity: shared molecular mechanisms. Curr Opin Neurobiol 11:568-578.

Bower AJ, Waddington G (1981) A simple operative technique for chronically severing the cerebellar peduncles in neonatal rats. J Neurosci Methods 4:181-188.

Cabelli RJ, Hohn A, Shatz CJ (1995) Inhibition of ocular dominance column formation by infusion of NT-4/5 or BDNF. Science 267:1662-1666.

Celio MR (1990) Calbindin D-28k and parvalbumin in the rat nervous system. Neuroscience 35:375-475.

Cesa R, Morando L, Strata P (2005) Purkinje cell spinogenesis during architectural rewiring in the mature cerebellum. Eur J Neurosci 22:579-586.

Changeux JP, Danchin A (1976) Selective stabilisation of developing synapses as a mechanism for the specification of neuronal networks. Nature 264:705-712.

Chedotal A, Sotelo C (1993) The "creeper stage" in cerebellar climbing fiber synaptogenesis precedes the "pericellular nest" - ultrastructural evidence with parvalbumin immunocytochemistry. Brain Res Dev Brain Res 76:207-220.

Crepel F, Mariani J, Delhaye-Bouchaud N (1976) Evidence for a multiple innervation of Purkinje cells by climbing fibers in the immature rat cerebellum. J Neurobiol 7:567-578.

Dixon KJ, Sherrard RM (2006) Brain-derived neurotrophic factor induces post-lesion transcommissural growth of olivary axons that develop normal climbing fibers on mature Purkinje cells. Exp Neurol 202:44-56.

Eccles JC, Llinas R, Sasaki K (1966) The excitatory synaptic action of climbing fibres on the purkinje cells of the cerebellum. J Physiol (Lond) 182:268-296.

Fournier B, Rovira C, Mailly P, Fuhrman Y, Mariani J (2002) HRP injection in lobule VI-VII of the cerebellar cortex reveals a bilateral inferior olive projection in granuloprival rats. J Comp Neurol 449:65-75.

Fournier B, Lohof AM, Bower AJ, Mariani J, Sherrard RM (2005) Developmental modifications of olivocerebellar topography: the granuloprival cerebellum reveals multiple routes from the inferior olive. J Comp Neurol 490:85-97.

Fremeau Jr RT, Troyer MD, Pahner I, Nygaard GO, Tran CH, Reimer RJ, Bellocchio EE, Fortin D, Storm-Mathisen J, Edwards RH (2001) The expression of vesicular glutamate transporters defines two classes of excitatory synapse. Neuron 31:247-260.

Fuhrman Y, Thomson MA, Piat G, Mariani J, Delhaye-Bouchaud N (1994) Enlargement of olivo-cerebellar microzones in the agranular cerebellum of adult rats. Brain Res 638:277-284.

Gardette R, Crepel F, Alvarado-Mallart RM, Sotelo C (1990) Fate of grafted embryonic Purkinje cells in the cerebellum of the adult "Purkinje cell degeneration" mutant mouse. II. Development of synaptic responses: an in vitro study. J Comp Neurol 295:188-196.

Hashimoto K, Kano M (2003) Functional differentiation of multiple climbing fiber inputs during synapse elimination in the developing cerebellum. Neuron 38:785-796.

Hashimoto K, Kano M (2005) Postnatal development and synapse elimina- tion of climbing fiber to Purkinje cell projection in the cerebellum. Neurosci Res 53:221-228.

Ichikawa R, Miyazaki T, Kano M, Hashikawa T, Tatsumi H, Sakimura K, Mishina M, Inoue Y, Watanabe M (2002) Distal extension of climbing fiber territory and multiple innervation caused by aberrant wiring to adjacent spiny branchlets in cerebellar Purkinje cells lacking glutamate receptor $\delta 2$. J Neurosci 22:8487-8503.

Jontes JD, Phillips GR (2006) Selective stabilization and synaptic specificity: a new cell-biological model. Trends Neurosci 29:186-191.

Kakizawa S, Yamasaki M, Watanabe M, Kano M (2000) Critical period for activity-dependent synapse elimination in developing cerebellum. J Neurosci 20:4954-4961.

Katz LC, Shatz CJ (1996) Synaptic activity and the construction of cortical circuits. Science 274:1133-1138.

Konnerth A, Llano I, Armstrong CM (1990) Synaptic currents in cerebellar Purkinje cells. Proc Natl Acad Sci USA 87:2662-2665.

Kossel AH, Williams CV, Schweizer M, Kater SB (1997) Afferent innervation influences the development of dendritic branches and spines via both activity-dependent and non-activity-dependent mechanisms. J Neurosci 17:6314-6324.

Larramendi EM (1969) Analysis of synaptogenesis in the cerebellum of the mouse. In: Neurobiology of cerebellar evolution and development (Llinas R, ed), pp 803-843. Chicago: American Medical Association.

Larramendi EM, Victor T (1967) Synapses on the Purkinje cell spines in the mouse. An electronmicroscopic study. Brain Res 5:15-30.

Laxson LC, King JS (1983) The development of the Purkinje cell in the cerebellar cortex of the opossum. J Comp Neurol 214:290-308.

Llano I, Marty A, Armstrong CM, Konnerth A (1991) Synaptic- and agonist-induced excitatory currents of Purkinje cells in rat cerebellar slices. J Physiol (Lond) 434:183-213.

Lohof AM, Delhaye-Bouchaud N, Mariani J (1996) Synapse elimination in the central nervous system: functional significance and cellular mechanisms. Rev Neurosci 7:85-101.

Lohof AM, Mariani J, Sherrard RM (2005) Afferent-target interactions during olivocerebellar development: transcommissural reinnervation indicates interdependence of Purkinje cell maturation and climbing fibre synapse elimination. Eur J Neurosci 22:2681-2688.

Mariani J (1982) Extent of multiple innervation of Purkinje cells by climbing fibers in the olivocerebellar system of weaver, reeler, and staggerer mutant mice. J Neurobiol 13:119-126.

Mariani J (1983) Elimination of synapses during the development of the central nervous system. Prog Brain Res 58:383-392.

Mariani J, Changeux JP (1980) Multiple innervation of Purkinje cells by climbing fibers in the cerebellum of the adult staggerer mutant mouse. J Neurobiol 11:41-50.

Mariani J, Changeux JP (1981a) Ontogenesis of olivocerebellar relationships. I. Studies by intracellular recordings of the multiple innervation of Purkinje cells by climbing fibers in the developing rat cerebellum. J Neurosci 1:696-702.

Mariani J, Changeux JP (1981b) Ontogenesis of olivocerebellar relationships. II. Spontaneous activity of inferior olivary neurons and climbing fibermediated activity of cerebellar Purkinje cells in developing rats. J Neurosci 1:703-709.

Mariani J, Crepel F, Mikoshiba K, Changeux JP, Sotelo C (1977) Anatomical, physiological and biochemical studies of the cerebellum from Reeler mutant mouse. Philos Trans R Soc Lond B Biol Sci 281:1-28.

Mariani J, Benoit P, Hoang MD, Thomson MA, Delhaye-Bouchaud N (1990) Extent of multiple innervation of cerebellar Purkinje cells by climbing fibers in adult X-irradiated rats. Comparison of different schedules of irradiation during the first postnatal week. Brain Res Dev Brain Res 57:63-70.

Mason CA, Christakos S, Catalano SM (1990) Early climbing fiber interactions with Purkinje cells in the postnatal mouse cerebellum. J Comp Neurol 297:77-90.

Miyazaki T, Fukaya M, Shimizu H, Watanabe M (2003) Subtype switching of vesicular glutamate transporters at parallel fibre-Purkinje cell synapses in developing mouse cerebellum. Eur J Neurosci 17:2563-2572.

Moon M, Gomez TM (2006) Multiple signaling pathways mediate biphasic BDNF-induced changes in growth cone motility. Soc Neurosi Abstr 32: 124.11.

Palay SL, Chan-Palay V (1974) Cerebellar cortex: cytology and organization. Berlin: Springer. 
Purves D, Lichtman JW (1980) Elimination of synapses in the developing nervous system. Science 210:153-157.

Rabacchi S, Bailly Y, Delhaye-Bouchaud N, Mariani J (1992a) Involvement of the N-methyl D-aspartate (NMDA) receptor in synapse elimination during cerebellar development. Science 256:1823-1825.

Rabacchi SA, Bailly Y, Delhaye-Bouchaud N, Herrup K, Mariani J (1992b) Role of the target in synapse elimination: studies in cerebellum of developing lurcher mutants and adult chimeric mice. J Neurosci 12:4712-4720.

Ramon y Cajal S (1911) Histologie du système nerveux de l'homme et des vertébrés. Paris: Maloine.

Ritzenthaler S, Suzuki E, Chiba A (2000) Postsynaptic filopodia in muscle cells interact with innervating motoneuron axons. Nat Neurosci 3:1012-1017.

Rossi F, Wiklund L, van der Want JJ, Strata P (1991a) Reinnervation of cerebellar Purkinje cells by climbing fibres surviving a subtotal lesion of the inferior olive in the adult rat. I. Development of new collateral branches and terminal plexuses. J Comp Neurol 308:513-535.

Rossi F, van der Want JJ, Wiklund L, Strata P (1991b) Reinnervation of cerebellar Purkinje cells by climbing fibres surviving a subtotal lesion of the inferior olive in the adult rat. II. Synaptic organization on reinnervated Purkinje cells. J Comp Neurol 308:536-554.

Rossi F, Borsello T, Strata P (1992) Embryonic Purkinje cells grafted on the surface of the cerebellar cortex integrate in the adult unlesioned cerebellum. Eur J Neurosci 4:589-593.

Rossi F, Borsello T, Strata P (1994) Embryonic Purkinje cells grafted on the surface of the adult uninjured rat cerebellum migrate in the host parenchyma and induce sprouting of intact climbing fibres. Eur J Neurosci 6:121-136.

Scelfo B, Strata P, Knopfel T (2003) Sodium imaging of climbing fiber innervation fields in developing mouse Purkinje cells. J Neurophysiol 89:2555-2563.

Segal M, Greenberger V, Korkotian E (2003) Formation of dendritic spines in cultured striatal neurons depends on excitatory afferent activity. Eur J Neurosci 17:2573-2585.

Sherrard RM, Bower AJ (2001) BDNF and NT3 extend the critical period for developmental climbing fibre plasticity. NeuroReport 12:2871-2874.
Sherrard RM, Bower AJ (2003) IGF-1 induces neonatal climbing-fibre plasticity in the mature rat cerebellum. NeuroReport 14:1713-1716.

Sherrard RM, Bower AJ, Payne JN (1986) Innervation of the adult rat cerebellar hemisphere by fibres from the ipsilateral inferior olive following unilateral neonatal pedunculotomy: an autoradiographic and retrograde fluorescent double-labelling study. Exp Brain Res 62:411-421.

Singh KK, Miller FD (2005) Activity regulates positive and negative neurotrophin-derived signals to determine axon competition. Neuron 45:837-845.

Sotelo C (2004) Cellular and genetic regulation of the development of the cerebellar system. Prog Neurobiol 72:295-339.

Sotelo C, Alvarado-Mallart RM (1987) Embryonic and adult neurons interact to allow Purkinje cell replacement in mutant cerebellum. Nature 327:421-423.

Sotelo C, Hillman DE, Zamora AJ, Llinas R (1975) Climbing fiber deafferentation: its action on Purkinje cell dendritic spines. Brain Res 98:574-581.

Sotelo C, Alvarado-Mallart RM, Gardette R, Crepel F (1990) Fate of grafted embryonic Purkinje cells in the cerebellum of the adult "Purkinje cell degeneration" mutant mouse. I. Development of reciprocal graft-host interactions. J Comp Neurol 295:165-187.

Sugihara I, Lohof AM, Letellier M, Mariani J, Sherrard RM (2003) Postlesion transcommissural growth of olivary climbing fibres creates functional synaptic microzones. Eur J Neurosci 18:3027-3036.

Tempia F, Bravin M, Strata P (1996) Postsynaptic currents and short-term synaptic plasticity in Purkinje cells grafted onto an uninjured adult cerebellar cortex. Eur J Neurosci 8:2690-2701.

Yamagata M, Sanes JR, Weiner JA (2003) Synaptic adhesion molecules. Curr Opin Cell Biol 15:621-632.

Yuste R, Bonhoeffer T (2004) Genesis of dendritic spines: insights from ultrastructural and imaging studies. Nat Rev Neurosci 5:24-34.

Zagrebelsky M, Strata P, Hawkes R, Rossi F (1997) Reestablishment of the olivocerebellar projection map by compensatory transcommissural reinnervation following unilateral transection of the inferior cerebellar peduncle in the newborn rat. J Comp Neurol 379:283-299. 